\title{
Self-Reported and Objectively Measured Physical Activity of Elderly Women in Podgorica
}

\author{
Katarina Dragutinovic ${ }^{1}$ \\ ${ }^{1}$ University of Montenegro, Faculty for Sport and Physical Education, Niksic, Montenegro
}

\begin{abstract}
The aim of this paper was to determine the physical activity of elderly women and to analyze the age-related decline in physical activity in older women. The survey was conducted in Podgorica, on a sample of 100 participants. For the age-group comparisons we subdivided the sample younger group (77 participants aged 50-59 years) and older group (23 participants aged 60-69 years). In this research, the long form of the IPAQ questionnaire for self-evaluation was used containing four types questions of Physical Activity: work-related, transportation, housework/gardening and leisure-time activities. The three levels of physical activity suggested for classifying the populations are low, moderate, and high. If one takes into account the type of physical activity, the results indicate that there is a statistically significant difference between the younger and older elderly group of respondents in variables: total walking and overall stressful activities. Our research has shown that, overall, the group respondents from 50 to 59 years is more active than the group from 60 to 69 years of respondents. It has been determined that women of the third age are physically active and there is a statistically significant difference between the two sub-samples when it comes to overall physical activity, or rather that it decreases with age.
\end{abstract}

Key words: IPAQ Questionnaire, Older Adult, Female, Aging, Physical Activity

\section{Uvod}

Fizička aktivnost je svaka djelatnost u kojoj dominira tjelesno kretanje sa većim ili manjim fizičkim naprezanjem (Flander, 1984). Predstavlja jedan od najvažnijih koraka u poboljšanju zdravlja. Nepravilan način ishrane i manjak fizičke aktivnosti su glavni faktori rizika za nastanak hroničnih bolesti. Redovna umjerena fizička aktivnost smanjuje rizik od nastanka srčanih bolesti, moždanog udara, osteoporoze, dijabetesa, depresije, gojaznosti i itd (Bjelica, 2005; 2006a). Kada je u pitanju gojaznost, znamo da je ona uzrokovana nepravilnom ishranom i smanjenom fizičkom aktivnošću. Najnovija istraživanja pokazuju da se broj gojaznih osoba sve više povećava. U nezdravoj prehrambenoj tranziciji, povećanje hrane koja je siromašna hranljivim materijama, može nepovoljno djelovati na rast i razvoj, uz povećanje tjelesne težine kod djece, adolescenata i odraslih, što dovodi do veće tjelesne težine i loših zdravstvenih ishoda (Bjelica, 2006b). Napori u prevenciji prevelike tjelesne težine i gojaznosti kod djece i adolescenata $\mathrm{u}$ populaciji treba da se podudaraju sa poboljšanjem pristupa zdravstvenim intervencijama. Upravljanje težinom i smanjenjem negativnih efekata gojaznosti, uključuje intenzivnu terapiju radi promjene ishrane i vježbanja tokom čitavog života (Bjelica \& Popovic, 2017). Fizička aktivnost ima veliki uticaj na socijalizaciju starijih ljudi, zapravo može služiti za smanjenje socijalne isključenosti starijih ljudi, proširenje njihove društvene mreže i poboljšanje njihovog zdravlja. (Popovic \& Bjelica, 2017)

Prirodni proces starenja neminovno nosi mnogobrojne strukturne i morfološke promjene u organizmu koje se odražavaju na svakodnevni život pojedinaca, zato se sve više postavlja pitanje kako na najbolji način prihvatiti proces starenja. Uspješno starenje obuhvata više dimenzija zdravlja. Ono podrazumijeva fizičko, funkcionalno, socijalno i psihološko blagostanje. (Phelan, 2004).

Mnogi dokazi upućuju na to da je fizička aktivnost sredstvo za smanjenje morbiditeta i mortaliteta (Bouchard, Bla-

Correspondence:

Montenegro K. Dragutinovic

Sport University of Montenegro, Faculty for Sport and Physical Education, Narodne omladine bb, 81400 Niksic, Montenegro E-Mail: katarinadragutinovic24@gmail.com 
ir, \& Haskell, 2007; Bjelica, 2002). Benefiti fizičke aktivnosti uključuju: smanjenje tjelesne težine i procenata masti u tijelu, smanjenje krvnog pritiska, nivoa lipida i glukoze u krvi, a to sve utiče na zdrastveno stanje. Fizička neaktivnost povezana je sa povećanim rizikom od gojaznosti, hipertenzije i dijabetesa (Bouchard et al., 2007; Patterson, 2004). Dokazano je i da nedovoljna i smanjena fizička aktivnost dovodi do narušavanja zdravlja starijih ljudi, zato ih treba podsticati na nove izazove (Bjelica i Fratić, 2011; Bjelica, 2004).

Nepravilna, nedovoljna i neredovna fizička aktivnost postala je sastavni dio svakodnevnog života. Iskustva u svijetu i kod nas, pokazuju neophodnost promjene rizičnog ponašanja i formiranje zdravih navika u sklopu zdravog načina života, a sve u cilju očuvanja i unapređenja zdravlja stanovništva. Iako je napredak nauke i poboljšanje kvaliteta života rezultiralo povećanjem starijih u ukupnom broju stanovnika, neophodno je održavanje kvaliteta života starijih osoba (Bjelica i Krivokapić, 2011). Neophodno je pridržavati se preporuka Svjetske zdrastvene organizacije za vježbanje starijih odraslih osoba. One podrazumijevaju da pored redovnog vježbanja moramo voditi računa da vježbanje bude pravilno. Vježbe snage se moraju primjenjivati zajedno sa kardiovaskularnim vježbama, a ne kao samostalan način vježbanja (Franklin, Whaley, Howley, Balady, \& American College of Sports Medicine, 2000). Nalazi iz ove studije pokazuju da fizička aktivnost u grupama može da se koristi za smanjenje socijalne isključenosti starijih ljudi.

Rezultati istraživanja pokazuju da se na godišnjem nivou gubi približno $6 \%$ mišićne mase nakon 50 . godine života (Lynch et al., 1999), s tim što se $12 \%$ mišične mase može povećati nakon nekoliko mjeseci treninga snage (Lynch et al., 1999). Istraživanja su pokazala da se broj padova povećava za 35-40\% nakon 60 godine starosti (Hornbrook et al., 1994; Hayes, Myers, \& Robinovitch, 1996) i predstavlja posljedicu smanjenja mišićne snage, balansa i fleksibilnosti kod starijih osoba.

Efekti sistematskih fizičkih aktivnosti na mišićni sistem kod osoba koje stare su veoma impresivni. Zato rezultati dobro planiranog, naučno zasnovanog programa treninga otpora i snage mogu biti spektakularni. Od svih sistema tijela, neuromuskularni sistem može demonstrirati najvidljivije dramatične razlike između kompletno sedentarne, neaktivne osobe i osobe koja konstantno trenira u svim životnim dobima. U velikom broju istraživanja je potvrđeno da starije osobe koje ostanu fizički aktivne imaju veće nivoe snage nego neaktivne osobe, što sve upućuje na povezanost fizičke aktivnosti i psihomotornih funkcija kod starijih (Bjelica i Krivokapić, 2010, 2012).

Primarni cilj ovog istraživanja je da utvrdi nivo fizičke aktivnosti žena starijih od 50 godina, a mlađih od 70 godina. Sekundarni cilj je da utvrdi postoji li razlika u nivou fizičke aktivnosti grupe žena od 50 do 59 godina, upoređujući ih sa ženama od 60 do 69 godina starosti.

\section{Metod}

Istraživanje je sprovedeno na uzorku od 100 ispitanica, koje žive na teritoriji Podgorice. Uzorak je podijeljen na dva subuzorka (tabela 1). Po kriterijumu hronološke starosti prvom pripada 77 ispitanica (mlađa grupa od 50-59), a 23 ispitanica pripada drugom subuzorku (starija grupa od 60-69). Žene koje su uključene u istraživanje stanuju u gradskim naseljima, njih 23\% (23 ispitanice) su u radnom odnosu, a ostale su nezaposlene ili penzionerke $77 \%$ (77 ispitanica). Od starijeg uzorka u radnom odnosu su samo dvije žene, što znači da ostatak žena koje rade pripada mlađem uzorku (21-a ispitanica). Kriterijumi za uključivanje u istraživanje bili su starosna dob i pol.

Tabela 1. Uzorak ispitanika

\begin{tabular}{ccc}
\hline Godine starosti & Broj & Procenat(\%) \\
\hline $50-59$ & 77 & 77 \\
$60-69$ & 23 & 23 \\
Ukupno & 100 & 100 \\
\hline
\end{tabular}

Samoprocjena fizičke aktivnosti ispitanica izvršena je međunarodnim IPAQ upitnikom - International Physical Activity Questionaire. Upitnik procjenjuje fizičku aktivnost $\mathrm{u}$ više domena: fizičke aktivnosti na poslu, fizičke aktivnosti u prevozu, fizičke aktivnosti u dvorištu i kući i fizičke aktivnosti u slobodnom vremenu. Pored toga, upitnik sadrži pitanja vezana za sjedenje, koja u ovom istraživanju nisu razmatrana. Izvršeno je računanje za svaku stavku posebno (teške aktivnosti, umjerene aktivnosti i hodanje) prema IPAQ uputstvu, kako bismo odredili vrijeme fizičke aktivnosti ispitanica tokom jedne nedelje u odnosu na težinu aktivnosti koje su sprovodile. Takođe, izvršeno je izračunavanje Metabolic Equivalent Task (MET) za svaki tip fizičke aktivnosti posebno (posao, prevoz, domaćinstvo i slobodno vrijeme). Ukupni nedeljni nivo fizičke aktivnosti (MET-min/week) dobijen je pojedinačnim zbrajanjem MET vrijednosti za svaku stavku.

Teške aktivnosti definišu se kao aktivnosti u kojima ispitanici dišu mnogo dublje nego obično. To mogu biti aktivnosti kao što je dizanje teških stvari, kopanje, teški građevinski radovi ili penjanje stepenicama. Umjerene tjelesne aktivnosti su one koje podrazumijevaju nešto teže disanje nego uobičajeno, a mogu uključivati aktivnosti kao što su nošenje lakog tereta. Hodanje ne podrazumijeva umjerene tjelesne aktivnosti. Kod teških i umjerenih aktivnosti uzete su u obzir samo one koje su trajale najmanje deset minuta u kontinuitetu.

Za izračunavanje MET vrijednosti korišteni su sljedeći koeficijenti: naporne fizičke aktivnosti =8.0 METs, umjerene fizičke aktivnosti $=4.0$ METs i hodanje $=3.3$ METs.

$\mathrm{Za}$ obradu podataka dobijenih istraživanjem koristili smo deskriptivnu statistiku. Primjenom iste je izračunata aritmetička sredina i standardna devijacija. Princip bodovanja je prikazan prema IPAQ parametrima (MET vrijednosti), pomoću kojih smo utvrdili koliko su fizički aktivne žene treće dobi. Zatim, da bismo utvrdili da li postoji statistički značajna razlika u fizičkoj aktivnosti između dva subuzorka koristili smo se diskriminativnom statistikom, $\mathrm{t}$-testom na nivou značajnosti $\mathrm{q}=0.01$.

\section{Rezultati}

Nakon sprovedenog istraživanja, na teritoriji Podgorice, $u$ tabeli 2. prikazani su rezultati aktivnosti ispitanica u proteklih sedam dana. Rezultati pokazuju kolika je ukupna aktivnost že- 
na trećeg doba na poslu, u prevozu, domaćinstvu i slobodnom vremenu (hodanje, umjerene i naporne aktivnosti). Data je i statistički značajna razlika u nivou aktivnosti koja se javlja među grupama.

Tabela 2. Aktivnost ispitanica u proteklih 7 dana

\begin{tabular}{lccc}
\hline Dobijene MET vrijednosti & $\begin{array}{c}\mathbf{5 0 - 5 9} \\
(\boldsymbol{n}=\mathbf{7 7})\end{array}$ & $\begin{array}{c}\mathbf{6 0 - 6 9} \\
(\boldsymbol{n = 2 3 )}\end{array}$ & $\mathbf{q}$ \\
\hline Ukupna fizička aktivnost na poslu (MET) & $9435.31 \pm 4456.33$ & $5265 \pm 2481.94$ & $\mathbf{0 . 0 0}$ \\
Ukupna fizička aktivnost u prevozu (MET) & $176.00 \pm 88.00$ & $249.61 \pm 124.80$ & $\mathbf{0 . 0 0}$ \\
Ukupna fizička aktivnost u domaćinstvu (MET) & $2065.02 \pm 973.45$ & $1973.98 \pm 930.54$ & 0.34 \\
Ukupna fizička aktivnost u slobodnom vremenu (MET) & $52.32 \pm 24.66$ & $55.70 \pm 26.25$ & 0.56 \\
Ukupne aktivnosti hodanje (MET) & $2842.33 \pm 1339.88$ & $1790.11 \pm 843.86$ & $\mathbf{0 . 0 0}$ \\
Ukupne umjerene aktivnosti (MET) & $5253.59 \pm 2101.43$ & $5138.20 \pm 2055.28$ & 0.41 \\
Ukupne naporne aktivnosti (MET) & $3632.73 \pm 1712.55$ & $15.98 \pm 7.53$ & $\mathbf{0 . 0 0}$ \\
Ukupne fizičke aktivnosti (MET) & $11728.67 \pm 5078,66$ & $7544,29 \pm 3266,77$ & $\mathbf{0 . 0 0}$ \\
\hline
\end{tabular}

MET-metabolička jedinica, q- statistički značajna razlika utvrđena t-testom.

Kada je u pitanju potrošnja energije procijenjena IPAQ upitnikom, ukupna fizička aktivnost na poslu je najdominantnija, a nakon nje i ukupne umjerene aktivnosti koje su dominantne u odnosu na ukupno hodanje i ukupne naporne aktivnosti, bez obrzira na starosnu dob. Utvrđene su statistički značajne razlike između dva subuzorka u: ukupnoj fizičkoj aktivnosti na poslu, ukupnoj fizičkoj aktivnosti u prevozu, ukupnoj fizičkoj aktivnosti u hodanju i ukupnoj napornoj aktivnosti. Ukupna fizička aktivnost na osnovu zbrajanja nam je potvrdila da su žene trećeg doba fizički aktivne, kao i da sa godinama opada fizička aktivnost.

\section{Diskusija}

S obzirom da su rezultati pokazali opadanje fizičke aktivnost kod žena trećeg doba sa godinama, što potvrđuju niže MET vrijednosti većine varijabli, trebalo bi naglasiti da su ovi rezultati usaglašeni sa rezultatima prethodnih istraživanja (Ljumović, 2017; Mitrović, 2018; Popovic, Bjelica, Vukotic, \& Masanovic, 2018). Rezultati u literaturi ukazuju na to da se pad fizičkih aktivnosti povećava sa godinama. U centalnoj regiji, na teritoriji Podgorice, dobijeni rezultati ukazuju da žene koje pripadaju mlađem uzorku pokazuju bolje rezultate u fizičkoj aktivnosti u odnosu na stariju grupu (Ljumović, 2017). Istraživanja koja su sprovedena pokazuju da je fizička aktivnost dosta zastupljena kod cjelokupnog ispitivanog uzorka i da je starija grupa manje aktivna od mlađe grupe. Takođe, opadanje fizičkih aktivnosti sa godinama pokazuju istraživanja koja su sprovedena na suprotnom polu u centralnoj regiji (Mitrović, 2018). Ono što je veoma zapaženo kod ovih istraživanja, bez obzira na pol, jeste da su ljudi, godinama sve manje aktivni (Masanovic, Vukotic, Bjelica, \& Popovic, 2018). Što ukazuje da se mora raditi na promovisanju fizičkih aktivnosti i dobrobiti koje ona nudi starijim osobama.

Iz navedenih rezultata možemo zaključiti da su žene trećeg doba fizički najaktivne na poslu, gdje su veoma zastupljene naporne aktivnosti. Posao i aktivnosti koje se sprovode u okviru posla, pokazuju da postoji statistički značajna razlika između mlađeg i starijeg uzorka, u korsit mlađih žena. Ovaj podatak je dobijen na osnovu nivoa aktivnosti (umjerena i naporna aktivnost). Tome je doprinijelo to što je kod starijeg uzorka $\mathrm{u}$ radnom odnosu manji broj ispitanica, a i poslovi koje obavljaju su lakši.

Ukupna fizička aktivnost u prevozu je dobijena u korist starijih žena, što je veoma iznenađujuće pozitivan rezultat, jer su parametri koji su korišćeni u ovom izračunavanju bili hodanje i vožnja bicikla. Gdje su žene iz starijeg uzorka dosta vremena hodale u svrhu prevoza. Ostale aktivnosti nam ukazuju na to da žene ove dobi dosta fizičkih aktivnosti sprovode u domaćinstvu. Što i nije tako čudno, s obzirom da imamo podatak da su nezaposlene ili penzionerke, pa dosta vremena ostaje za rad u kući. Podatak koji nam ukazuje da žene minimalno ispunjavaju svoje slobodno vrijeme za fizičke aktivnosti je veoma zabrinjavajuć, jer po dobijenim rezultatima nijedan od dva subuzorka ne koristi fizičku aktivnost u slobodnom vremenu, tačnije u svrsi rekreacije.

Međutim, iako je stariji uzorak imao bolji rezultat kada je u pitanju hodanje u svrhu prevoza, kod ukupnog zbrajanja svih fizičkih aktivnosti u okviru hodanja (posao, prevoz i rekrecija), rezultati su ipak bili statistički značajni u korist mlađeg uzorka. Kada su u pitanju ukupne umjerene aktivnosti, primjećujemo da su one kod oba subuzorka na zadovoljavajućem nivou, što znači da su obje grupe umjereno fizički aktivne u toku nedelje i tu nemamo statistički značajnu razliku. Što nije slučaj kod napornih aktivnosti, gdje imamo statistički značajnu razliku između uzoraka, u korist mlađe grupe. Tim rezultatima su doprinijele naporne aktivnosti na poslu, kojima su izložene žene iz mlađeg uzorka, jer je više žena iz mlađeg uzorka koje su u radnom odnosu. Starija grupa, kako je već navedeno, nije izložena napornim aktivnostima na poslu. Ovaj podatak nije dovoljno pouzdan za zaključivanje na većem nivou jer su samo 23 žene u radnom odnosu, od kojih samo dvije pripadaju starijem uzorku.

$\mathrm{Na}$ osnovu preporuka Svjetske zdrastvene organizacije, koja predlaže da se umjerene fizičke aktivnosti i hodanje obavljaju od $4000 \mathrm{MET}$ minut/nedjelja do $10000 \mathrm{MET}$ minut/ nedjelja, ili obavljanje izrazito napornih fizičkih aktivnosti od $600 \mathrm{MET}$ minut/nedjelja do $4000 \mathrm{MET}$ minut/nedjelja. Dobijeni rezultati ukazuju da su žene trećeg doba zadovoljavajuće fizički aktivne u ukupnim umjerenim fizičkim aktivnostima, dok su kod ukupnog hodanja daleko ispod prosjeka. Kada su u pitanju naporne aktivnosti tu mlađi uzorak ima zadovoljavajuće rezultate, dok stariji uzorak ima minimalne. Potrošnja energije procijenjena IPAQ upitnikom, ukazuje da je ukupna umjerena fizička aktivnost dominantna u odnosu na ukupno hodanje i ukupne naporne aktivnosti bez obrzira na starosnu dob. Statistički značajna razlika se najviše ogleda na nivou fizičke aktivnosti na poslu i ukupnih napornih aktivnosti, dok se u ostalim nivoima malo razlikuju. 
Ukupna fizička aktivnost koja je dobijena zbrajanjem dobijenih podataka nam ukazuje na to da postoji statistički značajna razlika između mlađeg i starijeg uzorka, u korist mlađeg uzorka. Ukupne MET vrijednosti nam ukazuju na to da su žene koje pripadaju starosnoj grupi od 50-59 godina, fizički aktivnije od žena koje pripadaju starosnoj grupi od 60-69 godina, na osnovu čega zaključujemo da fizička aktivnost opada s godinama.

S obzirom na već utvrđeni značaj fizičke aktivnosti na zdravlje i sprečavanje bolesti kod starijih ljudi, treba ciljnu grupu više podsticati na bavljenje fitnesom ili nekom drugom fizičkom aktivnosti u vidu rekreacije. Treba obratiti pažnju na preporuke Svjetske zdravstvene organizacije. Ona usmjerava na svakodnevno brzo hodanje, $u$ trajanju od 30 minuta, koje ne mora biti izvedeno u kontinuitetu, već može biti podijeljeno na 2 ili 3 dijela, što je podjednako efikasno. Za osobe koje su starije potrebno je, prije svega, napraviti pojedinačnu procjenu zdravstvenog statusa i na osnovu nje odrediti vrstu i programe rekreativnih aktivnosti koje su adekvatne njihovom psihofizičkom statusu. Uglavnom, preporučuje se hodanje različitog intenziteta, aktivan boravak na svježem vazduhu, raznovrsne vježbe koje povećavaju pokretljivost zglobova, a sve to treba da prati uravnotežena ishrana i adekvatan režim odmora. (Bjelica, 2012)

Svrha ovog istraživanja bila je da se utvrdi fizička aktivnost žena trećeg doba u Podgorici. Dobijeni rezultati nisu pozitivni i ukazuju na to da su žene sa godinama sve manje fizički aktivne. Imajući u vidu koliko je fizičko vježbanje važno radi očuvanja zdravlja, ovi rezultati mogu podstaći promovisanje fizičkih aktivnosti, zapravo, dobrobiti koje ona nudi starijim osobama.

\section{Acknowledgements}

There are no acknowledgements.

\section{Conflict of Interest}

The authors declare that there are no conflict of interest.

Received: 05 January 2018| Accepted: 16 March 2018| Published: 13 July 2018

\section{References}

Bjelica, D. (2002). Opšti pojmovi sportskog treninga: (skraćena verzija). Podgorica.

Bjelica, D. (2004). Uticaj sportskog treninga na antropomotoričke sposobnosti: (fudbalskih kadeta Crne Gore). Podgorica: Crnogorska sportska akademija.

Bjelica, D. (2005). Sistematizacija sportskih disciplina i sportski trening. Podgorica: Crnogorska sportska akademija.

Bjelica, D. (2006a). Sportski trening. Podgorica: Crnogorska sportska akademija.
Bjelica, D. (2006b). Teorijske osnove tjelesnog i zdravstvenog obrazovanja. Podgorica: Crnogorska sportska akademija.

Bjelica, D., i Fratrić, F. (2011). Sportski trening: teorija, metodika i dijagnostika. Nikšić: Fakultet za sport i fizičko vaspitanje.

Bjelica, D., i Krivokapić, D. (2011). Teorija igre. Nikšić: Fakultet za sport i fizičko vaspitanje Univerziteta Crne Gore.

Bjelica, D, i Krivokapić, D. (2010). Teorijske osnove fizičke kulture. Nikšić: Fakultet za sport i fizičko vaspitanje Univerziteta Crne Gore

Bjelica D. (2012). Rekreacija za svako životno doba. Medical, 40, 36-7.

Bjelica D., i Krivokapić D. (2012). Uticaj fizičkog vježbanja na psihomotorne funkcije starijih osoba. Zbornik radova Druge međunarodne konferencije Sportske nauke i zdravlje, Banja Luka: Panevropski univerzitet APEIRON, 191-96.

Bjelica, D. (2013). Teorija sportskog treninga. Podgorica: Univerzitet Crne Gore. Bouchard, C., Blair, S. N., \& Haskell, W. L. (Ed.). (2007). Physical activity and health. Champaign, IL: Human Kinetics I.

Flander, M. (1984). Sportski leksikon. Zagreb: Jugoslovenski leksikografski zavod Miroslav Krleža.

Franklin, B.A., Whaley, M.H., Howley, E.T., Balady, G.J., \& American College of Sports Medicine. (2000). ACSM's Guidelines for Exercise Testing and Prescription. Philadelphia: Lippincott Williams \& Wilkins, 223- 30.

Hayes, W. C., Myers, E. R., \& Robinovitch, S. N. (1996). Etiology and prevention of age-related hip fractures. Bone, 18(1), 77-86.

Hornbrook, M. C., Stevens, V. J., Wingfield, D. J., Hollis, J.F., Greenlick, M.R., \& Ory, M.G. (1994). Preventing falls among community dwelling older persons: results from a randomized trial. Gerontologist, 34(1), 16-23.

NCD Risk Factor Collaboration. (2017). Worldwide trends in body-mass index, underweight, overweight, and obesity from 1975 to 2016: a pooled analysis of 2416 populationbased measurement studies in 128.9 million children, adolescents, and adults [published online October 10, 2017]. Lancet. doi: 10.1016/S0140-6736(17)32129-3

Ljumović, P. (2017). Fizička aktivnost starijih žena u Podgorici, u odnosu na njihovu starosnu dob. Diplomski rad, Nikšić: Fakultet za sport i fizičko vaspitanje.

Lynch, N. A., Metter, E. J., Lindle, R. S., Fozard, J.L., Tobin, J.D., Roy, T.A., Fleg, J.L., \& Hurley, B.F. (1999). Muscle quality I: ageassociated differences in arm vs leg muscle groups. Journal fo Applied Physiology, 86(1), 188-94.

Masanovic, B., Vukotic, M., Bjelica, D., \& Popovic, S. (2018). Describing Physical Activity Profile of Older Montenegrin Males Using the International Physical Activity Questionnaire (IPAQ). In Book of Abstracts 15th International Scientific Conference on Transformation Process in Sport "Sport Performance" (61), Podgorica: Montenegrin Sports Academy.

Mitrović, M. (2018). Self-Reported and Objectively Measured Physical Activity of Males from 50 to 69 Years Old. Jaspe, 2(2), 99-101.

Patterson, P. D., Moore, C. G., Probst, J. C., \& Shinogle, J. A. (2004). Obesity and physical inactivity in rural America. The Journal of Rural Health, 20(2), 151-9.

Phelan E. A., Anderson, L. A., LaCroix, A. Z., \& Larson, E. B. (2004). Older adults views of "successful aging" - how do they compare with researcher's definitions? J Am Geriatr Soc., 52, 211-6.

Popović, S., \& Bjelica, D. (2017). Effects of physical activity on social exclusion among older people: a literature review. In Conference Book of Abstract of the 8th Conference of HEPA Europe, "Modern Approaches to Physical Activity promotion and measurement" (122). Zagreb: HEPA Europe.

Popovic, S., Bjelica, D., Vukotic, M., \& Masanovic, B. (2018). Describing Physical Activity Profile of Older Montenegrin Females Using the International Physical Activity Questionnaire (IPAQ). In Book of Abstracts 15th International Scientific Conference on Transformation Process in Sport "Sport Performance" (60-61), Podgorica: Montenegrin Sports Academy. 